\title{
Antivirals for COVID-19 in Solid Organ Transplant Recipients
}

\author{
Justin C. Laracy ${ }^{1} \cdot$ Elizabeth C. Verna ${ }^{2} \cdot$ Marcus R. Pereira ${ }^{1}$ (it)
}

Accepted: 12 October 2020 / Published online: 21 October 2020

(C) Springer Nature Switzerland AG 2020

\begin{abstract}
Purpose of Review To evaluate the critical studies published so far on the most promising antiviral therapies for COVID-19, with particular emphasis on any solid organ transplant-specific information.

Recent Findings Although the literature is increasing exponentially, most clinical trials have been preliminary, thus lacking robust evidence to support many of the drugs discussed here. The main exception is remdesivir, for which several trials have been published supporting its use for patients with severe COVID-19. No solid organ transplant-specific data on remdesivir or other antiviral therapies have been published so far.

Summary While further studies are urgently needed, in particular those specific to solid organ transplant recipients, the evidence so far only supports the use of remdesivir for patients with severe COVID-19.
\end{abstract}

Keywords Remdesivir $\cdot$ Convalescent plasma $\cdot$ COVID-19 $\cdot$ Solid organ transplant $\cdot$ SARS-CoV-2

\section{Introduction}

The outbreak of the novel severe acute respiratory syndrome coronavirus 2 (SARS-CoV-2) in Wuhan, China, in December 2019 evolved into a global pandemic that by July 2020 has led to over 16 million cases and 600,000 deaths worldwide [1]. Though the pathogenesis of coronavirus disease 2019 (COVID-19) remains incompletely understood, the spectrum of clinical manifestations ranges from asymptomatic disease to acute respiratory distress syndrome with septic shock and multiorgan failure [2,3]. Approximately $14 \%$ of patients with COVID-19 suffer severe cases and 5\% are categorized as critical [4]. The reported mortality rate of patients with COVID-19 has varied significantly, with figures ranging from 2.3 to $7.2 \%$ overall and up to $61.5 \%$ among critically ill

This article is part of the Topical Collection on COVID19 and Transplantation

Marcus R. Pereira

mp2323@cumc.columbia.edu

1 Department of Medicine, Division of Infectious Disease, Columbia University College of Physicians \& Surgeons, 622 W 168th St PH 876 W, New York, NY 10032, USA

2 Department of Medicine, Division of Digestive \& Liver Diseases, Columbia University College of Physicians \& Surgeons, New York, NY, USA patients [4-6]. Comorbidities including diabetes mellitus, hypertension, obesity, coronary artery disease, chronic kidney disease, and chronic lung disease are widely recognized as risk factors for severe disease [3].

Solid organ transplant (SOT) recipients are generally at increased risk of viral, bacterial, and fungal infections, and infection remains an important cause of post-SOT mortality. However, whether chronic immunosuppression in SOT with COVID-19 is either protective against or a risk factor for severe COVID-19 is an area of intense investigation, evolving since the initial stages of the outbreak [7]. As such, management of immunosuppression in SOT patients with COVID-19 remains uncertain [8]. Early case reports from China described favorable outcomes among heart and kidney transplant recipients with COVID-19 $[9,10]$. A more recent study of 47 SOT recipients, when compared to a matched group of non-SOT recipients with COVID-19, showed that transplant status itself was not associated with increased mortality [11]. Nevertheless, other studies from Europe and North America have indicated worse outcomes in this population [12-14]. While this remains to be determined, defining effective and safe therapies will be important in this vulnerable population.

In this article, we aim to review the existing antiviral treatments for COVID-19 with a focus on the unique challenges among SOT recipients. We will review the evidence in support of the use of these antiviral medications, in particular remdesivir and convalescent plasma, the 2 most promising antiviral therapies at this time. We will conclude with a 
discussion on the use of antivirals for prophylaxis against SARS-CoV-2 infection in SOT patients.

\section{SARS-CoV-2 Life Cycle and Pathogenesis}

Understanding the life cycle of SARS-CoV-2 is key to the development of effective antiviral therapies. As a member of the Coronaviridae family, SARS-CoV-2 is a positive-sensed singlestranded, enveloped RNA virus. Like other coronaviruses, SARS-CoV-2 has four structural proteins: the $\mathrm{S}$ (spike) glycoprotein, E (envelope) glycoprotein, M (membrane) glycoprotein, and $\mathrm{N}$ (nucleocapsid) protein. The $\mathrm{S}, \mathrm{E}$, and $\mathrm{M}$ glycoproteins together create the viral envelope while the $\mathrm{N}$ protein binds the virion RNA [15]. Critically, the $\mathrm{S}$ protein mediates virion attachment and fusion with the host cell via the cell surface angiotensin-converting enzyme 2 (ACE2) receptor [16].

The coronavirus life cycle consists of four phases. In the first attachment and entry phase, the S glycoprotein binds to the ACE2 receptor on the surface of host cells. This interaction governs tissue tropism of the virus, with ACE2 found in various organs including the lungs, heart, kidneys, and gastrointestinal tract [17]. Once encapsulated within an endosome, acid-dependent proteolytic cleavage of the $\mathrm{S}$ protein allows for fusion of the viral and cellular membranes with subsequent release of the viral genome into the cytoplasm [18]. In the second and third phases, virion mRNA undergoes translation to produce polyproteins, which are cleaved to yield a replicase-transcriptase complex. The process ultimately leads to the creation of more viral genomic and subgenomic mRNA. In the final assembly and release phase, subgenomic mRNA is translated into the virion structural proteins. The antiviral agents to be discussed below each target a specific step in the viral life cycle. For example, remdesivir and favipiravir inhibit the viral RNA polymerase, hydroxychloroquine putatively blocks the attachment and entry phase, and protease inhibitors act to prevent the cleavage of polyproteins.

It is believed that subsequent to the initial viral replication phase of the infection, a dysregulated immune response results in a cytokine storm leading to the most severe manifestations [19]. Conceptually, this has led to the breakdown of COVID-19 into 3 stages: an early viral replication phase, an intermediary phase, and a more severe hyper inflammatory phase (Fig. 1). Therapeutically, the emphasis has been on antiviral drugs early in the infection and anti-inflammatory agents later in the disease process.

\section{Antiviral Agents}

At this time, there are no Food and Drug Administration (FDA)-approved drugs for the treatment of COVID-19 and all agents are considered investigational. Though data are beginning to emerge on a variety of antiviral drugs that target
SARS-CoV-2, few have shown conclusive results via randomized controlled trials. While some agents under consideration have clear antiviral mechanisms of action (remdesivir), others are postulated to have dual antiviral and immunomodulatory activity (convalescent plasma) (Table 1). To our knowledge, no trials have explicitly excluded SOT recipients.

Although little is known about the viral kinetics of SARSCoV-2 in immunocompromised patients, extrapolating from other viral infections in this population has raised the concern for a rapid rise in viral burden, wider dissemination, and more prolonged viral shedding in SOT patients [20,21]. If this is the case, there may be reason to be concerned that antiviral therapy for COVID-19 in SOT could be less effective and be more susceptible to the development of resistance [22].

\section{Remdesivir}

Remdesivir (GS-5734) is a nucleotide analog prodrug that acts as an inhibitor of the viral RNA-dependent RNA polymerase. First developed by Gilead Sciences in 2009 for the treatment of hepatitis $\mathrm{C}$ and respiratory syncytial virus, remdesivir has since been shown to exhibit broad-spectrum antiviral activity [23]. In light of past evidence of activity against SARS-CoV-1 and Middle East respiratory syndrome (MERS-CoV), there was an early interest in its use as a therapeutic candidate for SARS-CoV-2 [24-27].

Initial in vitro studies showed that remdesivir effectively inhibited SARS-CoV-2 [28]. Subsequently, a rhesus macaque model of SARS-CoV-2 infection showed that remdesivir was associated with a significant reduction in bronchoalveolar lavage viral load and decreased pulmonary infiltrates [29]. Remdesivir was also shown to inhibit SARS-CoV-2 replication in human bronchial epithelial cells [30]. Given the absence of alternative treatment options and the progressive nature of the pandemic, these studies encouraged the use of remdesivir on the grounds of "compassionate use." In an uncontrolled case series of 53 hospitalized patients from 9 countries who received from 1 to 10 days of compassionate use of remdesivir, Grein et al. reported clinical improvement in 68\% of patients [31]. Patients were included if they had an oxygen saturation of $94 \%$ or less on ambient air or if they required oxygen support. In this group, $57 \%$ and $8 \%$ required mechanical ventilation and extracorporeal membrane oxygenation (ECMO) at baseline, respectively. During a median followup of 18 days, 36 patients (68\%) had an improvement in category of oxygen support.

Subsequently, there have been several prospective clinical trials investigating the use of remdesivir for the treatment of COVID-19 (summarized in Table 2). In the first randomized, double-blind, placebo-controlled trial conducted with remdesivir, 236 patients were randomly assigned 2:1 to a 10-day course of remdesivir ( $200 \mathrm{mg}$ on day 1 followed by $100 \mathrm{mg}$ on days $2-10$ ) or placebo. Inclusion criteria were 
Fig. 1 COVID-19 disease progression

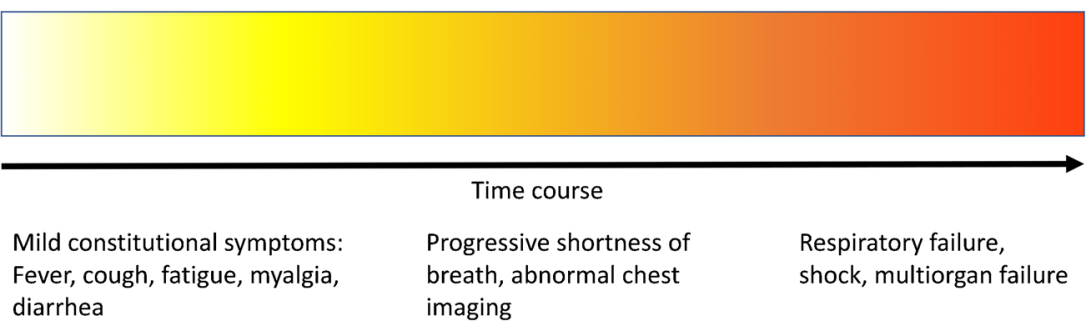

interval from symptom onset to enrollment of 12 days or less, oxygen saturation of $94 \%$ or less on ambient air or a ratio of arterial oxygen partial pressure to fractional inspired oxygen of $300 \mathrm{mmHg}$ or less, and radiographically confirmed pneumonia. The trial found that there was no significant difference in time to clinical improvement, 28-day mortality, or rate of viral clearance among hospitalized patients with COVID-19 [32]. However, limitations to the study included obscured effects of remdesivir due to use of concomitant medications (corticosteroids, lopinavir/ritonavir, interferon) and an early termination due to lack of available patients in Wuhan by early Spring 2020, as it was originally powered for the inclusion of 453 patients, which may have statistically underpowered the trial [33].

The Adaptive COVID-19 Treatment Trial (ACTT-1) was a multinational, randomized, double-blinded, placebo-controlled trial funded by the National Institute of Allergy and Infectious Diseases. This trial evaluated

Table 1 Summary of antiviral agents for the treatment of COVID-19

\begin{tabular}{|c|c|c|c|}
\hline Agent & Mechanism & Toxicities & Considerations in SOT patients \\
\hline \multicolumn{4}{|l|}{ Currently recommended } \\
\hline Remdesivir & Inhibits viral RNA polymerase & $\begin{array}{l}\text { Acute kidney injury, elevated } \\
\text { transaminases }\end{array}$ & $\begin{array}{l}\text { Does not strongly interact with SOT } \\
\text { medications }\end{array}$ \\
\hline \multicolumn{4}{|c|}{ Recommended in the context of a clinical trial only } \\
\hline $\begin{array}{l}\text { Convalescent } \\
\text { plasma }\end{array}$ & $\begin{array}{l}\text { Passive immunity in the form of } \\
\text { neutralizing antibodies }\end{array}$ & $\begin{array}{l}\text { Allergic and transfusion-related reactions: } \\
\text { fevers, chills, dyspnea, progressing to } \\
\text { anaphylaxis, hemolysis, TACO, } \\
\text { TRALI }\end{array}$ & No specific considerations in SOT patients \\
\hline Hydroxychloroquine & $\begin{array}{l}\text { Inhibits glycosylation of host } \\
\text { receptors required for binding to } \\
\text { ACE2 receptor, inhibits endosomal } \\
\text { acidification required for viral entry }\end{array}$ & $\begin{array}{l}\text { Abdominal cramps, nausea, vomiting, } \\
\text { diarrhea, QTc prolongation. With } \\
\text { prolonged use: neuropsychiatric and } \\
\text { central nervous system side effects, } \\
\text { bone marrow suppression, retinal } \\
\text { toxicity }\end{array}$ & $\begin{array}{l}\text { Monitoring of QTc interval with } \\
\text { coadministration of calcineurin } \\
\text { inhibitors, mTOR inhibitors; inhibition } \\
\text { of cytochrome p450-2D6 pathway can } \\
\text { result in elevated levels of cyclosporine }\end{array}$ \\
\hline $\begin{array}{l}\text { Lopinavir-ritonavir, } \\
\text { and other PIs }\end{array}$ & $\begin{array}{l}\text { Inhibits } 3 C L \text { protease required for } \\
\text { maturation of viral polyproteins }\end{array}$ & $\begin{array}{l}\text { Rash (including SJS, TEN), nausea, } \\
\text { vomiting, diarrhea, elevated } \\
\text { transaminases, dysglycemia, } \\
\text { pancreatitis, QTc and PR interval } \\
\text { prolongation; high incidence of } \\
\text { drug-drug interactions }\end{array}$ & $\begin{array}{l}\text { Reduced clearance of glucocorticoids, } \\
\text { calcineurin inhibitors, mTOR } \\
\text { inhibitors; monitoring of QTc interval } \\
\text { as above }\end{array}$ \\
\hline Famotidine & Possible inhibition of $3 \mathrm{CL}$ protease & Headache, diarrhea, constipation & $\begin{array}{l}\text { May lead to reduced clearance of } \\
\text { cyclosporine }\end{array}$ \\
\hline \multicolumn{4}{|c|}{ Other investigational agents } \\
\hline REGN-CoV2 & $\begin{array}{l}\text { Dual neutralizing antibodies that bind } \\
\text { viral } \mathrm{S} \text { protein }\end{array}$ & Unknown & Unknown \\
\hline Favipiravir & Inhibits viral RNA polymerase & $\begin{array}{l}\text { Diarrhea, nausea, vomiting; } \\
\text { hyperuricemia, decreased neutrophils, } \\
\text { elevated transaminases }\end{array}$ & Unknown \\
\hline
\end{tabular}

3CL, 3-chymotrypsin-like; ACE2, angiotensin-converting enzyme 2; mTOR, mammalian target of rapamycin; PI, protease inhibitor; $S$, spike; SJS; Stevens-Johnson syndrome; SOT, solid organ transplant; TACO, transfusion-associated circulatory overload; TEN, toxic epidermal necrolysis; TRALI, transfusion-related acute lung injury 
Table 2 Summary of major trials of remdesivir for the treatment of COVID-19

\begin{tabular}{|c|c|c|c|c|}
\hline Study & Patients & Intervention & Results & Adverse events \\
\hline $\begin{array}{l}\text { Wang et al., } \\
\text { Remdesivir in } \\
\text { adults with severe } \\
\text { COVID-19 }\end{array}$ & $\begin{array}{l}236 \text { patients with } \mathrm{SpO}_{2} \leq 94 \% \\
\text { on } \mathrm{RA} \text { or } \mathrm{PaO}_{2} / \mathrm{FiO}_{2} \\
\leq 300 \mathrm{mmHg} \text { with } \\
\text { radiographic signs of PNA }\end{array}$ & $\begin{array}{l}\text {-Randomly } \\
\text { assigned 2:1 to } \\
\text { remdesivir or } \\
\text { placebo for } \\
10 \text { days } \\
\text {-Primary } \\
\text { outcome: time } \\
\text { to clinical } \\
\text { improvement }\end{array}$ & $\begin{array}{l}\text {-Remdesivir was not associated with } \\
\text { significant difference in time to } \\
\text { clinical improvement, mortality, } \\
\text { or time to viral clearance }\end{array}$ & $\begin{array}{l}\text {-Adverse events in } 66 \% \text { of patients } \\
\text { in the remdesivir group vs. } 64 \% \\
\text { of patients in placebo group } \\
\text {-Remdesivir stopped early because } \\
\text { of adverse events in } 12 \% \text { of } \\
\text { patients vs. } 5 \% \text { of patients in } \\
\text { placebo group }\end{array}$ \\
\hline Beigel et al., ACTT-1 & $\begin{array}{l}1063 \text { patients with either } \\
\text { radiographic infiltrates or } \\
\mathrm{SpO}_{2} \leq 94 \% \text { on } \mathrm{RA} \text { or } \\
\text { requiring oxygen support }\end{array}$ & $\begin{array}{l}\text {-Randomly } \\
\text { assigned } 1: 1 \text { to } \\
\text { remdesivir or } \\
\text { placebo for } \\
10 \text { days } \\
\text {-Primary } \\
\text { outcome: time } \\
\text { to recovery }\end{array}$ & $\begin{array}{l}\text {-Faster median recovery time with } \\
\text { remdesivir over placebo (11 vs. } \\
15 \text { days, } p<0.001 \text { ) } \\
\text {-Lower mortality in the remdesivir } \\
\text { group, but not significant (HR for } \\
\text { death } 0.70 \text { ) } \\
\text {-Benefit greatest in patients who } \\
\text { required supplemental oxygen } \\
\text { only }\end{array}$ & $\begin{array}{l}\text {-Serious adverse events in } 21.1 \% \text { of } \\
\text { patients in the remdesivir group } \\
\text { and } 27.0 \% \text { in placebo group }\end{array}$ \\
\hline $\begin{array}{l}\text { Goldman et al., } \\
\text { Remdesivir for } 5 \text { or } \\
10 \text { days in patients } \\
\text { with severe } \\
\text { COVID-19 }\end{array}$ & $\begin{array}{l}397 \text { patients with radiographic } \\
\text { infiltrates and either } \mathrm{SpO}_{2} \\
\leq 94 \% \text { on RA or requiring } \\
\text { supplemental oxygen }\end{array}$ & $\begin{array}{l}\text {-Randomly } \\
\text { assigned } 1: 1 \text { to } \\
\text { remdesivir for } \\
5 \text { or } 10 \text { days } \\
\text {-Primary } \\
\text { outcome: } \\
\text { clinical status } \\
\text { on day } 14\end{array}$ & $\begin{array}{l}\text {-No significant difference between } \\
\text { the 5-day and 10-day courses of } \\
\text { remdesivir } \\
-65 \% \text { of patients in the } 5 \text {-day group } \\
\text { and } 54 \% \text { of patients in } 10 \text {-day } \\
\text { group showed improvement in } \\
\text { clinical status at day } 14 \\
\text {-Time to clinical improvement was } \\
\text { similar in the 5-day and } 10 \text {-day } \\
\text { groups at } 10 \text { days vs. } 11 \text { days, } \\
\text { respectively }\end{array}$ & $\begin{array}{l}\text {-Percentages of patients with } \\
\text { adverse events were similar in the } \\
\text { two groups: } 70 \% \text { in the 5-day } \\
\text { group, } 74 \% \text { in the 10-day group } \\
\text {-Serious adverse events were more } \\
\text { common in the 10-day group } \\
(35 \%) \text { than in the 5-day group } \\
(21 \%)\end{array}$ \\
\hline
\end{tabular}

$R A$, room air; $\mathrm{PaO}_{2}$, arterial oxygen partial pressure; $\mathrm{FiO}_{2}$, fractional inspired oxygen; $\mathrm{PNA}$, pneumonia; $\mathrm{SpO}$, peripheral oxygen saturation; $\mathrm{HR}$, hazard ratio; $E C M O$, extracorporeal membrane oxygenation

1063 hospitalized patients with COVID-19. Patients were eligible if they had radiographic evidence of infiltrates or a peripheral oxygen saturation of $94 \%$ or less on ambient air or if they required supplemental oxygen, mechanical ventilation, or ECMO. Unlike the trial by Wang et al., there was no limit to the duration of symptoms prior to enrollment. The patients were randomized 1:1 to receive intravenous remdesivir or placebo for up to 10 days [34••]. Remdesivir treatment arm was significantly associated with reduced time to recovery (11 days versus 15 days), and the benefit was greatest in the subgroup of patients who required supplemental oxygen but who were not intubated. There was a nonsignificant trend towards improved survival with Kaplan-Meier estimates of mortality by 14 days of $7.1 \%$ and $11.9 \%$ in the remdesivir and placebo groups, respectively. Although there was no observed benefit in patients who were mechanically ventilated or on ECMO, the study may have been too short at just 29 days to detect a difference. Similarly, there was no observed benefit in the median time to recovery in patients with mild or moderate disease, although the numbers of participants in these categories were relatively small $[34 \bullet \bullet]$. The authors do not specifically mention whether SOT recipients were included in the study; however, $6.9 \%$ of overall participants had an immune deficiency (either acquired or innate), not including cancer.

When the interim results of ACTT-1 were released, Gilead simultaneously released the results of its multinational, randomized, open-label trial for patients with COVID-19 [35]. Inclusion criteria were similar to the above trials in that eligible patients had to have radiographic evidence of pulmonary infiltrates and either an oxygen saturation of $94 \%$ or less while they were breathing ambient air or were receiving supplemental oxygen. Any patients on mechanical ventilation or ECMO were excluded. In this trial, 397 hospitalized patients with COVID-19 were randomized to receive either a 5-day or 10-day course of remdesivir. Among patients who were not on mechanical ventilation or ECMO, there was no significant difference in clinic outcomes between these groups [36••]. SOT recipients were included in the study, although the exact number has not been released.

The FDA authorized Emergency Use Authorization (EUA) permission for remdesivir in COVID-19 on May 1, 2020. The 
FDA's release statement reports that, based on the available scientific evidence, "It is reasonable to believe that remdesivir may be effective in treating COVID-19, and that, given there are no adequate, approved, or available alternative treatments, the known and potential benefits to treat this serious or lifethreatening virus currently outweigh the known and potential risks of the drug's use." [37]. As a result of this, remdesivir is the only agent recommended by the Infectious Diseases Society of America (IDSA) and National Institutes of Health (NIH) guidelines outside of a clinical trial [38,39].

Generally, the trials cited above found that remdesivir was well-tolerated without a significant difference in rate of adverse effects compared to placebo. In the Wang et al. study and ACTT-1, the percentages of patients in the remdesivir arms versus placebo arms who experienced adverse events were $66 \%$ versus $64 \%$ and $21.1 \%$ versus $27.0 \%$, respectively $[32,34 \bullet \bullet]$. Similarly, the percentages of patients who experienced adverse events in the Gilead trial were similar: $70 \%$ in the 5-day group and 74\% in the 10-day group [36••]. Adverse effects that were frequently associated with remdesivir in these studies included gastrointestinal symptoms (anorexia, nausea, vomiting), hypotension, aminotransferase and bilirubin elevations, and acute kidney injury [32,34••,36••]. Generally, the incidence of adverse events was not significantly greater among patients who received remdesivir. For example, the percentages of patients in the remdesivir versus placebo groups who developed acute kidney injury and transaminase elevations in the ACTT-1 were $7.4 \%$ versus $7.3 \%$ and $4.1 \%$ versus $5.9 \%$, respectively [34••]. No SOT-specific data on adverse effects has been released so far.

There are no known drug interactions between remdesivir any of the commonly used immunosuppressive agents taken by SOT recipients [40]. However, transplant practitioners should be cautious when administering remdesivir to SOT patients with COVID-19 given the lack of studies evaluating its safety in this patient population. Particular caution must be taken in liver transplant recipients and other SOT recipients who may be at heightened risk of hepatic injury from remdesivir as well as those with chronic kidney disease, usually a major comorbidity in this population. For example, shared exclusion criteria by Wang et al. and ACTT-1 were transaminase elevations more than five times the upper limit of normal, renal impairment with an estimated glomerular filtration rate less than $30 \mathrm{~mL} / \mathrm{min}$, or renal replacement therapy $[32,34 \bullet \bullet]$. Nevertheless, there is general agreement that the potential benefits outweigh the potential risks of using remdesivir in SOT recipients with COVID-19, provided they meet the general guidance contained in the EUA.

Several mutations, in particular those involving the viral RNA-dependent RNA polymerase (RdRp), which could lead to remdesivir resistance have been described [41]. As an inhibitor of the RdRp, viral mutations that improve the fidelity of the base-pairing process could result in remdesivir resistance. In one study, induced mutations in a murine hepatitis virus rendered the virus strongly resistant to remdesivir [42]. Whether a similar mutation could occur under natural conditions in SARS-CoV-2 is unclear, and so far none has been reported, but this experiment sets a precedent for how remdesivir resistance could occur. The possibility of prolonged viral shedding due to immunosuppression could be a significant risk factor for the development of resistance among SOT patients.

There are several ongoing trials investigating remdesivir. For example, ACTT-2 is a study enrolling since May 2020. Structured in similar fashion to ACTT-1, it compares remdesivir versus a combination of remdesivir and baricitinib, a JAK inhibitor, for patients with severe COVID-19. Further data from this study, and others, will hopefully soon be available that could further clarify many questions including the roles of both antiviral and immunomodulatory therapies.

\section{Convalescent Plasma}

The use of convalescent plasma (CP) as a therapy for viral pneumonia was first investigated during the 1918 Spanish influenza pandemic [43]. CP has since been used to treat a diverse range of viral pneumonias including SARS-CoV-1 and MERS-CoV with the largest study performed in Hong Kong showing that among patients infected with SARSCoV-1, CP was associated with improved mortality [44]. CP provides passive immunity in the form of neutralizing antibodies collected from screened donor individuals. In SARSCoV-1 and SARS-CoV-2, the main antigenic target of neutralizing antibodies appears to be the S protein; thus, CP may act to inhibit cellular binding and entry of SARS-CoV-2 $[45,46]$.

Support for the use of CP to treat COVID-19 mainly comes from small observational trials. In a matched control trial of 39 patients classified as having severe to life-threatening COVID-19 treated with CP, plasma recipients had greater likelihood of stable or improved oxygen requirements with an adjusted analysis showing a survival benefit with $\mathrm{CP}$ in non-intubated patients (HR 0.19, $p=0.015$ ), but not for intubated patients [47•]. In an observational study of 46 patients with moderate-to-severe ARDS and need for mechanical ventilation or continuous positive airway pressure treated with $\mathrm{CP}$, there was a decrease in mortality at 7 days compared to a match cohort [48]. In an open-label, multicenter, randomized trial of 103 patients with severe or life-threatening COVID-19 at 7 centers in Wuhan, China, comparing standard care plus $\mathrm{CP}$ versus standard care alone, $\mathrm{CP}$ was associated with lower 28 -day mortality ( $24 \%$ vs. $16 \%$ ), greater likelihood of discharge by 28 days ( $36 \%$ vs. $51 \%$ ), and faster clinical improvement [49•]. However, none of these findings was clinically significant and interpretation of the results is limited by 
early termination of the trial due to insufficient eligible patients in the region of China where it was conducted.

$\mathrm{CP}$ has historically been considered a safe treatment with relatively few adverse side effects, including among SOT recipients. In the epidemics influenza A H1N1, SARS-CoV-1, and MERS-CoV, studies did not find any adverse effects consistently associated with CP [50]. Similar to any other human blood product, $\mathrm{CP}$ can cause various allergic and transfusionrelated reactions such as anaphylaxis, hemolysis, transfusionassociated circulatory overload, and transfusion-related acute lung injury. In trials investigating CP for COVID-19, adverse events have included fevers, chills, anaphylaxis, and transfusion-related acute lung injury $\left[48,49{ }^{\circ}\right]$. In the trial of 103 patients who received $\mathrm{CP}$, there were only two reported transfusion-related adverse events and both patients fully recovered with supportive care [49॰]. CP does not interact with any immunosuppressive medications prescribed to SOT patients and evidence for the use of CP to treat COVID-19 in SOT patients is limited to case reports [51,52].

\section{Hydroxychloroquine/Chloroquine}

In the initial stages of the pandemic, there was considerable interest in the use of hydroxychloroquine with and without azithromycin for the treatment of COVID-19. This interest was largely driven by in vitro data regarding the use of chloroquine for the treatment of the 2003 SARS-CoV-1 outbreak [53]. In general, hydroxychloroquine has less severe toxicities and fewer drug interactions than chloroquine [54].

There are two primary mechanisms by which hydroxychloroquine could inhibit SARS-CoV-2. In SARS$\mathrm{CoV}-1$, it was shown that chloroquine leads to a deficit of glycosylated receptors at the virus-cell interface required for efficient binding to ACE2 receptors [55]. Chloroquine also inhibits the endosomal acidification pathway required for SARS-CoV-2 entry into the cellular cytoplasm [56]. Because the $\mathrm{S}$ glycoprotein of SARS-CoV-2 also uses the ACE2 receptor, it was believed that hydroxychloroquine could be used to inhibit SARS-CoV-2 $[28,57]$.

The antiviral and anti-inflammatory actions of chloroquine/ hydroxychloroquine led to numerous early trials during the COVID-19 pandemic as well as inclusion as an off-label therapy in various initial center-specific guidances [58]. Unfortunately, subsequent large trials have failed to demonstrate benefits of hydroxychloroquine. A multicenter randomized open-label trial in France comparing hydroxychloroquine to standard of care showed no difference in viral clearance [59]. Similarly, a large observational study failed to show benefit or harm associated with hydroxychloroquine among over 1300 patients admitted to a quaternary care center in New York City [60••]. In addition, preliminary negative results in the Solidarity trial sponsored by the World Health Organization (WHO) led to the discontinuation of the hydroxychloroquine treatment arm on July 4, 2020. Based on these, and the potential for severe complications detailed below, the NIH COVID-19 Treatment Guidelines currently recommends against the use of chloroquine or hydroxychloroquine for the treatment of COVID-19 except as part of a clinical trial [39].

Individually, both hydroxychloroquine and azithromycin can cause disturbances in the cardiac conduction pathway leading to prolongation of the QT interval and predisposing to cardiac arrhythmias [61,62]. Several studies of patients hospitalized with COVID-19 have raised concerns over QT interval prolongation from chloroquine/hydroxychloroquine alone or in combination with azithromycin [63,64]. Both calcineurin inhibitors (CNIs), such as cyclosporine and tacrolimus, and mammalian target of rapamycin inhibitors (mTORs), such as sirolimus and everolimus, can also cause QT interval prolongation [65]. Careful monitoring of ECGs is critical for SOT patients on immunosuppressive agents who are treated with hydroxychloroquine and/or azithromycin for COVID-19. Another potential adverse effect of hydroxychloroquine in SOT patients is myelosuppression, although this would be unlikely to occur in the setting of short-term treatment of COVID-19. Regarding drug-drug interactions, chloroquine and hydroxychloroquine are moderate inhibitors of the cytochrome P450-2D6 pathway. There have been reports of SOT recipients who experienced a threefold increase in serum cyclosporine concentrations following initiation of chloroquine $[66,67]$. In summary, caution must be taken when starting hydroxychloroquine in SOT patients maintained on immunosuppressive medications that share similar metabolic pathways.

\section{Lopinavir-Ritonavir and Other Protease Inhibitors}

Another early consideration for the treatment of COVID-19 included lopinavir-ritonavir, a well-known but no longer widely used HIV protease inhibitor (PI). The replication cycle of SARS-CoV-2 depends on the cleavage of polyproteins into functional protein subunits via the action of proteases. It was found that lopinavir can inhibit one of the key proteases in SARS-CoV-1, 3-chymotrypsin-like protease (3CL protein), thereby disrupting viral replication [68]. Pharmacologically boosted lopinavir was found to have activity against SARSCoV-1 and MERS-CoV [69,70]. The 3CL protein appears to be highly conserved in SARS-CoV-2, which raised interest in the use of PIs as potential agents for the treatment of COVID19 [71].

In a randomized, controlled, open-label trial of nearly 200 hospitalized patients with COVID-19, treatment with lopinavir-ritonavir was not associated with a difference in time to clinical improvement or viral clearance over standard of care [72•]. However, in a modified intention-to-treat analysis, treatment with lopinavir-ritonavir did lead to a median time to 
clinical improvement that was shorter by 1 day [72•]. In a randomized controlled trial conducted in hospitalized patients with COVID-19 in China, there was no difference in efficacy between patients who received chloroquine and lopinavirritonavir [73]. However, with only 22 patients, this study likely had insufficient power to detect any clinical differences. Finally, because of preliminary negative results, the lopinavir-ritonavir treatment arm in the Solidarity trial sponsored by the WHO was discontinued on July 4, 2020.

PIs are known to cause impaired glucose tolerance, hepatotoxicity, and QT and PR interval prolongation [74-76]. The potential for PI-related QT interval prolongation is highly relevant for any SOT patient on azithromycinhydroxychloroquine, CNIs, or mTORs. PIs and their boosting agents are potent modulators of the hepatic cytochrome P4503A4 pathway, leading to altered metabolism of critical medications in SOT recipients [77]. PI-mediated inhibition of the P450-3A4 pathway can lead to significant reductions in glucocorticoid clearance [78]. By the same mechanism, administration of PIs to SOT recipients on CNIs and mTORs can lead to elevations in immunosuppressive medications with narrow therapeutic indices [79]. In order to avoid the dangerous side effects associated with elevated levels of steroids, CNIs, and mTORs, practitioners must adjust the dosing of these medications and carefully track their serum levels.

\section{Other Investigational Agents}

A variety of other antiviral medications are under investigation for the treatment of COVID-19. One novel agent under investigation for treatment and post-exposure prophylaxis of COVID-19 is REGN-CoV2. REGN-CoV2 is a cocktail of two virus-neutralizing antibodies that noncompetitively bind the critical receptor binding domain of the S protein of SARS-CoV-2, neutralizing the virus and preventing infection [80]. In a recent statement from Regeneron, there are three ongoing late-stage trials on REGN-CoV2 being performed in collaboration with the National Institute of Allergy and Infectious Diseases: two phase $2 / 3$ trials for the treatment of hospitalized and ambulatory patients with COVID-19 that will evaluate virologic and clinical endpoints and one phase 3 trial for post-exposure prophylaxis in individuals who have had a high-risk exposure to someone with confirmed COVID-19 [81].

Other agents include favipiravir, famotidine, nitazoxanide, ribavirin, ivermectin, zinc, and others [82-84]. Famotidine, which may act to inhibit the 3CL protease, has been found to be associated with reduced rick of clinical deterioration leading to intubation or death among hospitalized patients with COVID-19 [85]. Favipiravir is a broad-spectrum antiviral that inhibits viral RNA polymerase that is also being investigated as a potential therapeutic for COVID-19 [86]. These medications remain primarily investigational with limited data to support their use beyond clinical trials.

\section{Antivirals for Use as Prophylactic Agents Against COVID-19}

The publication of recent data suggesting the possibility of more severe outcomes from COVID-19 in SOT recipients highlights the need for medications for pre-exposure prophylaxis (PrEP) and post-exposure prophylaxis (PEP) against SARS-CoV-2 [12]. Though this has not yet been documented, this may be specifically important in SOT recipients given the risk of donor-derived SARS-CoV-2 exposure and infection.

In a preprint, non-peer-reviewed, retrospective cohort study of healthcare workers in India, it was found that PrEP with hydroxychloroquine was associated with an $80.7 \%$ reduction in risk of SARS-CoV-2 [87]. In a randomized, double-blind, placebo-controlled trial conducted in the USA and Canada of over 800 patients with SARS-CoV-2 exposure, there was no difference in the incidence of new illness from COVID-19 between participants who received hydroxychloroquine (11.8\%) and placebo (14.3\%) [88•]. There are various ongoing trials investigating chloroquine, hydroxychloroquine, and PIs for the use of PrEP and PEP against SARS-CoV-2 [89-91]. It should be noted that under the EUA, remdesivir is not permitted for the purposes of prophylaxis [92]. The NIH COVID-19 Treatment Guidelines does not recommend the use of any agents for PrEP or PEP against SARS-CoV-2 outside the setting of a clinical trial [39].

\section{Concluding Remarks}

The continued spread of the SARS-CoV-2 pandemic represents an international health crisis with the potential to impact SOT recipients across the globe. Currently, there are no trials investigating antiviral agents primarily in SOT recipients and the major studies published so far have included few patients with any form of immunosuppression, especially SOT recipients. Therefore, the clinical impact of remdesivir and other therapies can only be extrapolated from these non-transplant patient populations. Nevertheless, it is our opinion that the overall approach to antiviral therapy for COVID-19 in SOT recipients should be similar to the general population and that the general recommendations in the NIH and IDSA COVID19 guidelines should be applied to these patients as well $[38,39]$. From an antiviral perspective, that would primarily include early initiation of remdesivir when the clinical picture is in accordance with the EUA guidance.

Since December 2019, it is clear that our understanding of COVID-19 has progressed and treatment approaches have 
been rapidly refined. As of July 29, 2020, for example, over 100 interventional clinical trials are registered in clinicaltrials. gov, highlighting an unprecedented global effort. Nonetheless, further studies are urgently needed on several fronts including, among many others, understanding the role of chronic immunosuppression in the pathogenesis of SARSCoV-2 infection, identifying SOT-specific risk factors for severe COVID-19, discovering effective and safe antiviral treatments, and the optimal timing of therapy initiation in this unique and vulnerable patient population. On those multiple fronts, much work is needed.

\section{Compliance with Ethical Standards}

Conflict of Interest ECV is on the Gilead Advisory Board. MRP and JCL have no conflicts to declare.

Human and Animal Rights and Informed Consent This article does not contain any studies with human or animal subjects performed by any of the authors.

Abbreviations SARS-CoV-2, Severe acute respiratory syndrome coronavirus 2; COVID-19, Coronavirus disease; HCQ, Hydroxychloroquine; SOT, Solid organ transplant

\section{References}

Papers of particular interest, published recently, have been highlighted as:

- Of importance

•. Of major importance

1. Coronavirus disease (COVID-19). Accessed July 6, 2020. https:// www.who.int/emergencies/diseases/novel-coronavirus-2019? gclid=Cj0KCQjwrIf3BRD1ARIsAMuugNsOgasTzfhTZpL E N q d 4 p L W r 6 T A 1xPJjQr54oOVg5MrMhOG3 FCNMaAuS8EALw wcB

2. $\mathrm{Hu} \mathrm{Z}$, Song $\mathrm{C}, \mathrm{Xu} \mathrm{C}$, et al. Clinical characteristics of 24 asymptomatic infections with COVID-19 screened among close contacts in Nanjing, China. Sci China Life Sci. 2020;63(5):706-11. https://doi. org/10.1007/s11427-020-1661-4.

3. Richardson S, Hirsch JS, Narasimhan M, et al. Presenting characteristics, comorbidities, and outcomes among 5700 patients hospitalized with COVID-19 in the New York City area. JAMA Published online April 22, 2020. 2020. https://doi.org/10.1001/ jama.2020.6775.

4. Wu Z, McGoogan JM. Characteristics of and important lessons from the coronavirus disease 2019 (COVID-19) outbreak in China: summary of a report of 72314 cases from the Chinese Center for Disease Control and Prevention. JAMA. 2020;323(13): 1239-42. https://doi.org/10.1001/jama.2020.2648.

5. Onder G, Rezza G, Brusaferro S. Case-fatality rate and characteristics of patients dying in relation to COVID-19 in Italy. JAMA. 2020;323(18):1775-6. https://doi.org/10.1001/jama.2020.4683.

6. Yang $\mathrm{X}, \mathrm{Yu} \mathrm{Y}, \mathrm{Xu}$ J, et al. Clinical course and outcomes of critically ill patients with SARS-CoV-2 pneumonia in Wuhan, China: a single-centered, retrospective, observational study. Lancet Respir
Med. 2020;8(5):475-81. https://doi.org/10.1016/S2213-2600(20) 30079-5.

7. Thng ZX, de Smet MD, Lee CS, et al. COVID-19 and immunosuppression: a review of current clinical experiences and implications for ophthalmology patients taking immunosuppressive drugs. Br J Ophthalmol. 2020;bjophthalmol-2020-316586. https://doi.org/ 10.1136/bjophthalmol-2020-316586.

8. Fishman JA. The immunocompromised transplant recipient and SARS-CoV-2 infection. J Am Soc Nephrol. 2020;31(6):1147-9. https://doi.org/10.1681/ASN.2020040416.

9. Li F, Cai J, Dong N. First cases of COVID-19 in heart transplantation from China. J Heart Lung Transplant. 2020;39(5):496-7. https://doi.org/10.1016/j.healun.2020.03.006.

10. Zhu L, Xu X, Ma K, et al. Successful recovery of COVID-19 pneumonia in a renal transplant recipient with long-term immunosuppression. Am J Transplant. 2020;20(7):1859-63. https://doi. org/10.1111/ajt.15869.

11. Chaudhry ZS, Williams JD, Vahia A, et al. Clinical characteristics and outcomes of COVID-19 in solid organ transplant recipients: a case-control study. Am J Transplant. Published online July 12, 2020:ajt.16188. https://doi.org/10.1111/ajt.16188.

12. Pereira MR, Mohan S, Cohen DJ, et al. COVID-19 in solid organ transplant recipients: initial report from the US epicenter. Am J Transplant. 2020;20(7):1800-8. https://doi.org/10.1111/ajt.15941.

13. Akalin E, Azzi Y, Bartash R, et al. Covid-19 and kidney transplantation. N Engl J Med. 2020;382(25):2475-7. https://doi.org/10. 1056/NEJMc2011117.

14. Alberici F, Delbarba E, Manenti C, et al. A single center observational study of the clinical characteristics and short-term outcome of 20 kidney transplant patients admitted for SARS-CoV2 pneumonia. Kidney Int. 2020;97(6):1083-8. https://doi.org/10.1016/j.kint. 2020.04.002.

15. Astuti I. Ysrafil. Severe acute respiratory syndrome coronavirus 2 (SARS-CoV-2): an overview of viral structure and host response. Diabetes Metab Syndr Clin Res Rev. 2020;14(4):407-12. https:// doi.org/10.1016/j.dsx.2020.04.020.

16. Shang J, Wan Y, Luo C, et al. Cell entry mechanisms of SARSCoV-2. Proc Natl Acad Sci U S A. 2020;117(21):11727-34. https:// doi.org/10.1073/pnas.2003138117.

17. Hamming I, Timens W, Bulthuis MLC, Lely AT, Navis GJ, van Goor $\mathrm{H}$. Tissue distribution of ACE2 protein, the functional receptor for SARS coronavirus. A first step in understanding SARS pathogenesis. J Pathol. 2004;203(2):631-7. https://doi.org/10. 1002/path.1570.

18. Fehr AR, Perlman S. Coronaviruses: an overview of their replication and pathogenesis. In: Coronaviruses: methods and protocols, vol. 1282. New York: Springer; 2015. p. 1-23. https://doi.org/10. 1007/978-1-4939-2438-7_1.

19. $\mathrm{Fu} \mathrm{Y}$, Cheng Y, Wu Y. Understanding SARS-CoV-2-mediated inflammatory responses: from mechanisms to potential therapeutic tools. Virol Sin. 2020;12250. https://doi.org/10.1007/s12250-02000207-4.

20. Ison MG. Adenovirus infections in transplant recipients. Clin Infect Dis. 2006;43(3):331-9. https://doi.org/10.1086/505498.

21. de Lima CRA, Mirandolli TB, Carneiro LC, et al. Prolonged respiratory viral shedding in transplant patients. Transpl Infect Dis. 2014;16(1):165-9. https://doi.org/10.1111/tid.12167.

22. Amirian ES, Levy JK. Current knowledge about the antivirals remdesivir (GS-5734) and GS-441524 as therapeutic options for coronaviruses. One Health. 2020;9:100128. https://doi.org/10. 1016/j.onehlt.2020.100128.

23. Development of Remdesivir - Gilead. Accessed July 8, 2020. https://www.gilead.com/-/media/gilead-corporate/files/pdfs/covid19/gilead_rdv-development-fact-sheet-2020.pdf

24. Sheahan TP, Sims AC, Graham RL, et al. Broad-spectrum antiviral GS-5734 inhibits both epidemic and zoonotic coronaviruses. Sci 
Transl Med. 2017;9(396). https://doi.org/10.1126/scitranslmed. aal3653.

25. Brown AJ, Won JJ, Graham RL, et al. Broad spectrum antiviral remdesivir inhibits human endemic and zoonotic deltacoronaviruses with a highly divergent RNA dependent RNA polymerase. Antivir Res. 2019;169:104541. https://doi.org/10. 1016/j.antiviral.2019.104541.

26. Agostini ML, Andres EL, Sims AC, et al. Coronavirus susceptibility to the antiviral remdesivir (GS-5734) is mediated by the viral polymerase and the proofreading exoribonuclease. mBio. 2018;9(2). https://doi.org/10.1128/mBio.00221-18.

27. Sheahan TP, Sims AC, Leist SR, et al. Comparative therapeutic efficacy of remdesivir and combination lopinavir, ritonavir, and interferon beta against MERS-CoV. Nat Commun. 2020;11(1):114. https://doi.org/10.1038/s41467-019-13940-6.

28. Wang M, Cao R, Zhang L, et al. Remdesivir and chloroquine effectively inhibit the recently emerged novel coronavirus (2019$\mathrm{nCoV}$ ) in vitro. Cell Res. 2020;30(3):269-71. https://doi.org/10. 1038/s41422-020-0282-0.

29. Williamson BN, Feldmann F, Schwarz B, et al. Clinical benefit of remdesivir in rhesus macaques infected with SARS-CoV-2. bioRxiv. https://doi.org/10.1101/2020.04.15.043166.

30. Pizzorno A, Padey B, Julien T, et al. Characterization and treatment of SARS-CoV-2 in nasal and bronchial human airway epithelia. bioRxiv. Published online April 2, 2020:2020.03.31.017889. https://doi.org/10.1101/2020.03.31.017889.

31. Grein J, Ohmagari N, Shin D, et al. Compassionate use of remdesivir for patients with severe Covid-19. N Engl J Med. 2020;382(24):2327-36. https://doi.org/10.1056/NEJMoa2007016.

32. Wang Y, Zhang D, Du G, et al. Remdesivir in adults with severe COVID-19: a randomised, double-blind, placebo-controlled, multicentre trial. Lancet. 2020;395(10236):1569-78. https://doi. org/10.1016/S0140-6736(20)31022-9.

33. Singh AK, Singh A, Singh R, Misra A. Remdesivir in COVID-19: a critical review of pharmacology, pre-clinical and clinical studies. Diabetes Metab Syndr Clin Res Rev. 2020;14(4):641-8. https://doi. org/10.1016/j.dsx.2020.05.018.

34.• Beigel JH, Tomashek KM, Dodd LE, et al. Remdesivir for the treatment of Covid-19 — preliminary report. N Engl J Med. https://doi.org/10.1056/nejmoa2007764 Published online May 22, 2020. Multinational, randomized, double-blinded placebo-controlled trial of hospitalized patients with COVID-19 showing that remdesivir reduced time to clinical improvement, and that the benefit was most pronounced in patients who required supplemental oxygen but who were not intubated.

35. Gilead announces results from phase 3 trial of investigational antiviral remdesivir in patients with severe COVID-19. Accessed July 8, 2020. https://www.gilead.com/news-and-press/press-room/ press-releases/2020/4/gilead-announces-results-from-phase-3-trialof-investigational-antiviral-remdesivir-in-patients-with-severecovid-19

36.• Goldman JD, Lye DCB, Hui DS, et al. Remdesivir for 5 or 10 days in patients with severe Covid-19. N Engl J Med. https://doi.org/10. 1056/nejmoa2015301 Published online May 27, 2020. Industrysponsored, multinational, randomized, open-label trial showing that among hospitalized patients with COVID-19, remdesivir treatment for 5 or 10 days had similar clinical benefit.

37. Coronavirus (COVID-19) update: FDA issues emergency use authorization for potential COVID-19 treatment | FDA. Accessed July 8, 2020. https://www.fda.gov/news-events/pressannouncements/coronavirus-covid-19-update-fda-issuesemergency-use-authorization-potential-covid-19-treatment

38. Infectious Diseases Society of America Guidelines on the treatment and management of patients with COVID-19. Accessed July 27, 2020. https://www.idsociety.org/practice-guideline/covid-19-
guideline-treatment-and-management/IDSACOVID19treatmentguidelines.

39. Coronavirus Disease 2019 (COVID-19) treatment guidelines. Accessed July 26, 2020. https://www.covid19treatmentguidelines. nih.gov/NIHCOVID-19treatmentguidelines.

40. el Kassas M, Alboraie M. al Balakosy A, et al. Liver transplantation in the era of COVID-19. Arab J Gastroenterol. 2020;21(2):69-75. https://doi.org/10.1016/j.ajg.2020.04.019.

41. Shannon A, Le NTT, Selisko B, et al. Remdesivir and SARS-CoV2: structural requirements at both nsp12 RdRp and nsp14 exonuclease active-sites. Antivir Res. 2020;178:104793. https://doi.org/10. 1016/j.antiviral.2020.104793.

42. Agostini ML, Andres EL, Sims AC, et al. Coronavirus susceptibility to the antiviral remdesivir (GS-5734) is mediated by the viral polymerase and the proofreading exoribonuclease. mBio. 2018;9(2). https://doi.org/10.1128/mBio.00221-18.

43. Francis F, Hall M, Gaines A. Early use of convalescent serum in influenza. MIl Surg. 1920;47:177-9.

44. Cheng Y, Wong R, Soo YOY, et al. Use of convalescent plasma therapy in SARS patients in Hong Kong. Eur J Clin Microbiol Infect Dis. 2005;24(1):44-6. https://doi.org/10.1007/s10096-0041271-9.

45. Sun B, Feng Y, Mo X, et al. Kinetics of SARS-CoV-2 specific IgM and $\mathrm{IgG}$ responses in COVID-19 patients. Emerg Microbes Infect. 2020;9(1):940-8. https://doi.org/10.1080/22221751.2020. 1762515.

46. Wang C, Li W, Drabek D, et al. A human monoclonal antibody blocking SARS-CoV-2 infection. Nat Commun. 2020;11(1):1-6. https://doi.org/10.1038/s41467-020-16256-y.

47. Liu HST, Lin H-M, Baine I, et al. Convalescent plasma treatment of severe COVID-19: a matched control study. medRxiv. https://doi. org/10.1101/2020.05.20.20102236 Published online 2020 . Observational study showing that patients with COVID-19 who received $\mathrm{CP}$ had improved outcomes, including better survival in non-intubated patients.

48. Perotti C, Baldanti F, Bruno R, et al. Mortality reduction in 46 severe Covid-19 patients treated with hyperimmune plasma. A proof of concept single arm multicenter interventional trial. medRxiv. Published online 2020. https://doi.org/10.1101/2020.05. 26.20113373 .

49. Li L, Zhang W, Hu Y, et al. Effect of convalescent plasma therapy on time to clinical improvement in patients with severe and lifethreatening COVID-19: a randomized clinical trial. JAMA. https:// doi.org/10.1001/jama.2020.10044 Published online 2020. Multicenter, open-label, randomized trial showing that COVID-19 patients treated with CP had non-significant trends towards faster clinical improvement and decreased mortality.

50. Rojas M, Rodríguez Y, Monsalve DM, et al. Convalescent plasma in Covid-19: possible mechanisms of action. Autoimmun Rev. 2020;19(7):102554. https://doi.org/10.1016/j.autrev.2020.102554.

51. Lung transplant patient with COVID-19 recovers following plasma clinical trial - UChicago Medicine. Accessed July 29, 2020. https:// www.uchicagomedicine.org/forefront/coronavirus-disease-covid19/lung-transplant-patient-with-covid-19-recovers-followingplasma-clinical-trial

52. Jiang J, Miao Y, Zhao Y, et al. Convalescent plasma therapy: helpful treatment of COVID-19 in a kidney transplant recipient presenting with serve clinical manifestation and complex complications. Clin Transpl. Published online July 15, 2020. 2020. https://doi.org/ $10.1111 /$ ctr.14025.

53. Keyaerts E, Vijgen L, Maes P, Neyts J, van Ranst M. In vitro inhibition of severe acute respiratory syndrome coronavirus by chloroquine. Biochem Biophys Res Commun. 2004;323(1):264 8. https://doi.org/10.1016/j.bbrc.2004.08.085.

54. Liu J, Cao R, Xu M, et al. Hydroxychloroquine, a less toxic derivative of chloroquine, is effective in inhibiting SARS-CoV-2 
infection in vitro. Cell Discov. 2020;6(1):1-4. https://doi.org/10. 1038/s41421-020-0156-0.

55. Vincent MJ, Bergeron E, Benjannet S, et al. Chloroquine is a potent inhibitor of SARS coronavirus infection and spread. Virol J. 2005;2(1):69. https://doi.org/10.1186/1743-422X-2-69.

56. Al-Bari MAA. Targeting endosomal acidification by chloroquine analogs as a promising strategy for the treatment of emerging viral diseases. Pharmacol Res Perspect. 2017;5(1):293. https://doi.org/ 10.1002/prp2.293.

57. Colson P, Rolain JM, Raoult D. Chloroquine for the 2019 novel coronavirus SARS-CoV-2. Int J Antimicrob Agents. 2020;55(3): 105923. https://doi.org/10.1016/j.ijantimicag.2020.105923.

58. Singh AK, Singh A, Shaikh A, Singh R, Misra A. Chloroquine and hydroxychloroquine in the treatment of COVID-19 with or without diabetes: a systematic search and a narrative review with a special reference to India and other developing countries. Diabetes Metab Syndr Clin Res Rev. 2020;14(3):241-6. https://doi.org/10.1016/j. dsx.2020.03.011.

59. Tang W, Cao Z, Han M, et al. Hydroxychloroquine in patients with mainly mild to moderate coronavirus disease 2019: open label, randomised controlled trial. BMJ. 2020;369. https://doi.org/10. 1136/bmj.m1849.

$60 . \bullet$ Geleris J, Sun Y, Platt J, et al. Observational study of hydroxychloroquine in hospitalized patients with Covid-19. N Engl J Med. 2020;382(25):2411-8. https://doi.org/10.1056/ NEJMoa2012410 Large observational study showing that hydroxychloroquine for the treatment of COVID-19 was not associated with decreased risk of intubation or death.

61. Ray WA, Murray KT, Hall K, Arbogast PG, Stein CM. Azithromycin and the risk of cardiovascular death. N Engl J Med. 2012;366(20):1881-90. https://doi.org/10.1056/ NEJMoa1003833.

62. The cardiotoxicity of antimalarials . World Health Organization. Published October 2016. Accessed July 26, 2020. https://www. who.int/malaria/mpac/mpac-mar2017-erg-cardiotoxicity-reportsession2.pdf

63. Borba MGS, Val FFA, Sampaio VS, et al. Effect of high vs low doses of chloroquine diphosphate as adjunctive therapy for patients hospitalized with severe acute respiratory syndrome coronavirus 2 (SARS-CoV-2) infection: a randomized clinical trial. JAMA. 2020;3(4):e208857. https://doi.org/10.1001/jamanetworkopen. 2020.8857

64. Mercuro NJ, Yen CF, Shim DJ, et al. Risk of QT interval prolongation associated with use of hydroxychloroquine with or without concomitant azithromycin among hospitalized patients testing positive for coronavirus disease 2019 (COVID-19). JAMA Cardiol. Published online 2020. 2020. https://doi.org/10.1001/jamacardio. 2020.1834

65. Ikitimur B, Cosansu K, Karadag B, et al. Long-term impact of different immunosuppressive drugs on QT and PR intervals in renal transplant patients. Ann Noninvasive Electrocardiol. 2015;20(5): 426-32. https://doi.org/10.1111/anec.12225.

66. Finielz P, Gendoo Z, Chuet C, Guiserix J. Interaction between cyclosporin and chloroquine. Nephron. 1993;65(2):333. https:// doi.org/10.1159/000187506.

67. Nampoory MRN, Nessim J, Gupta RK, Johny K. v. Drug interaction of chloroquine with ciclosporin. Nephron. 1992;62(1):108-9. https://doi.org/10.1159/000187007.

68. Nukoolkarn V, Lee VS, Malaisree M, Aruksakulwong O, Hannongbua S. Molecular dynamic simulations analysis of ritronavir and lopinavir as SARS-CoV 3CLpro inhibitors. J Theor Biol. 2008;254(4):861-7. https://doi.org/10.1016/j.jtbi.2008.07. 030 .

69. Chan JF, Yao Y, Yeung M, et al. Treatment with lopinavir / ritonavir or interferon- $\beta 1 \mathrm{~b}$ improves outcome of MERS- CoV infection in a nonhuman primate model of common marmoset. J Infect Dis. 2015;212(2):1904-13. https://doi.org/10.1093/infdis/ jiv392.

70. Chu CM, Cheng VCC, Hung IFN, et al. Role of lopinavir/ritonavir in the treatment of SARS: initial virological and clinical findings. Thorax. 2004;59(3):252-6. https://doi.org/10.1136/thorax.2003. 012658 .

71. Liu X, Wang XJ. Potential inhibitors against 2019-nCoV coronavirus $\mathrm{M}$ protease from clinically approved medicines. J Genet Genomics. 2020;47(2):119-21. https://doi.org/10.1016/j.jgg.2020. 02.001.

72. Cao B, Wang Y, Wen D, et al. A trial of lopinavir-ritonavir in adults hospitalized with severe Covid-19. N Engl J Med. 2020;382(19):1787-99. https://doi.org/10.1056/NEJMoa2001282 Randomized, controlled, open-label trial of hospitalized patients with COVID-19 treated with lopinavir-ritonavir showing no benefit beyond standard of care.

73. Huang M, Tang T, Pang P, et al. Treating COVID-19 with chloroquine. J Mol Cell Biol. 2020;12(4):322. https://doi.org/10.1093/ JMCB/MJAA014.

74. Tsiodras S, Mantzoros C, Hammer S, Samore M. Effects of protease inhibitors on hyperglycemia, hyperlipidemia, and lipodystrophy: a 5-year cohort study. Arch Intern Med. 2000;160(13):2050-6. https://doi.org/10.1001/archinte.160.13. 2050.

75. Behrens G, Dejam A, Schmidt H, et al. Impaired glucose tolerance, beta cell function and lipid metabolism in HIV patients under treatment with protease inhibitors. AIDS. 1999;13(10). https://doi.org/ 10.1097/00002030-199907090-00001.

76. Soliman EZ, Lundgren JD, Roediger MP, et al. Boosted protease inhibitors and the electrocardiographic measures of QT and PR durations. AIDS. 2011;25(3):367-77. https://doi.org/10.1097/ QAD.0b013e328341dcc0.

77. Protease Inhibitors - an overview $\mid$ ScienceDirect Topics. Accessed July 9, 2020. https://www.sciencedirect.com/topics/neuroscience/ protease-inhibitors

78. Busse KH, Formentini E, Alfaro RM, Kovacs JA, Penzak SR Influence of antiretroviral drugs on the pharmacokinetics of prednisolone in HIV-infected individuals. J Acquir Immune Defic Syndr. 2008;48(5):561-6. https://doi.org/10.1097/QAI. 0b013e31817bebeb.

79. Elens L, Langman LJ, Hesselink DA, et al. Pharmacologic treatment of transplant recipients infected with SARS-CoV-2: considerations regarding therapeutic drug monitoring and drug-drug interactions. Ther Drug Monit. 2020;42(3):360-8. https://doi.org/10. 1097/FTD.0000000000000761.

80. Hansen J, Baum A, Pascal KE, et al. Studies in humanized mice and convalescent humans yield a SARS-CoV-2 antibody cocktail. Science:eabd0827. Published online June 15, 2020. https://doi. org/10.1126/science.abd0827.

81. Regeneron announces start of REGN-COV2 phase 3 COVID-19 prevention trial in collaboration with National Institute of Allergy and Infectious Diseases (NIAID) | Regeneron Pharmaceuticals Inc. Accessed July 9, 2020. https://investor.regeneron.com/newsreleases/news-release-details/regeneron-announces-start-regncov2-phase-3-covid-19-prevention

82. New antiviral drugs for treatment of COVID-19 - Full Text View ClinicalTrials.gov. Accessed July 9, 2020. https://clinicaltrials.gov/ ct2/show/study/NCT04392427

83. Cai Q, Yang M, Liu D, et al. Experimental treatment with favipiravir for COVID-19: an open-label control study. Engineering. Published online March 18, 2020. 2020. https://doi. org/10.1016/j.eng.2020.03.007.

84. Furuta Y, Gowen BB, Takahashi K, Shiraki K, Smee DF, Barnard DL. Favipiravir (T-705), a novel viral RNA polymerase inhibitor. 
Antivir Res. 2013;100(2):446-54. https://doi.org/10.1016/j. antiviral.2013.09.015.

85. Freedberg DE, Conigliaro J, Wang TC, et al. Famotidine use is associated with improved clinical outcomes in hospitalized COVID-19 patients: a propensity score matched retrospective cohort study. Gastroenterology. Published online 2020. https://doi. org/10.1053/j.gastro.2020.05.053.

86. Cai Q, Yang M, Liu D, et al. Experimental treatment with favipiravir for COVID-19: an open-label control study. Engineering. Published online March 18, 2020. 2020. https://doi. org/10.1016/j.eng.2020.03.007.

87. Bhattacharya R, Chowdhury S, Mukherjee R, et al. Pre exposure hydroxychloroquine use is associated with reduced COVID19 risk in healthcare workers. medRxiv. Published online June 22, 2020: 2020.06.09.20116806. https://doi.org/10.1101/2020.06.09. 20116806.

88. Boulware DR, Pullen MF, Bangdiwala AS, et al. A randomized trial of hydroxychloroquine as postexposure prophylaxis for Covid-19. N Engl J Med. Published online June 3, 2020. https://doi.org/10.1056/ nejmoa2016638 Randomized, double-blind, placebo-controlled trial showing no benefit of hydroxychloroquine for use as postexposure prophylaxis against COVID-19.

89. Post-exposure prophylaxis / preemptive therapy for SARSCoronavirus-2 - Full Text View - ClinicalTrials.gov. Accessed July 9, 2020. https://clinicaltrials.gov/ct2/show/NCT04308668

90. Pre-exposure prophylaxis for SARS-Coronavirus-2 - Full Text View - ClinicalTrials.gov. Accessed July 9, 2020. https:// clinicaltrials.gov/ct2/show/study/NCT04328467

91. TAF/FTC for pre-exposure prophylaxis of COVID-19 in healthcare workers (CoviPrep Study) - Full Text View - ClinicalTrials.gov. Accessed July 9, 2020. https://clinicaltrials.gov/ct2/show/study/ NCT04405271

92. World Health Organisation. Frequently asked questions on the emergency use authorization for remdesivir for certain hospitalized COVID-19 patients.; 2020. Accessed July 28, 2020. https://www. fda.gov/media/137574/download

Publisher's Note Springer Nature remains neutral with regard to jurisdictional claims in published maps and institutional affiliations. 